\title{
APPRAISING THE LEVEL OF PARTICIPATION IN EARLY CHILDHOOD EDUCATION BY PUBLIC AND PRIVATE SCHOOLS IN NORTH CENTRAL NIGERIA
}

YISA, M. H. $\quad$ FASASI, Y. A.

Dept. of Educational Management, University of Ilorin, Nigeria

KWASHABAWA, B. B.

Dept. of Educational Foundations, Usmanu Danfodiyo University, Sokoto, Nigeria

\begin{abstract}
This study investigated the level of participation in Early Childhood Education (ECE) by public and private schools in North-central, Nigeria. The objectives of this study were to determine: (i) the level of participation by public schools in ECE; (ii) the level of participation by private schools in ECE (iv) whether there is difference in the level of participation by public and private in ECE schools in Nigeria. The descriptive survey design was employed for the study. The target population comprised 4,378 ECE school head teachers in North-central, Nigeria. Random and proportional sampling techniques were used to select a sample of 1,531 ECE school head teachers. A validated instrument entitled "Public and Private Schools Participation Questionnaire" (PPSPQ) with 0.72 and index was used to collect data. Mean and rank-ordering were used to answer research questions. Independent ttest was used to test the hypothesis at 0.05 significance level. Findings of this study revealed that public schools had medium level participation (teacher quality mean $=45.1$, supervision mean $=34.5$, curriculum implementation mean $=44.5$ and provision of facilities mean $=24.2$ ). It was also found that private schools had high level of participation (teacher quality mean $=42.2$, supervision mean $=$ 65.6, curriculum implementation mean $=54.7$, and provision of facilities $=56.4$ ). It was recommended that the government should participate fully in the education of pre-schoolers and upgrade the current low level of ECE facilities in public schools. Frequent visitation of public and private schools by quality assurance officers of ministries of education should be carried out to improve the quality of ECE provision in schools.
\end{abstract}

\section{Introduction}

Education is a foundation and building block of any meaningful development be it social, physical, economic or emotional. The beginning of education is said to be from birth and do not end till the death of an individual. Also, it is a means to the overall development of the individual and the society. Education is a solid base which serves as a means for social, physical, economic or emotional development of a child. Early Childhood Education (ECE) is the education given in preparation for primary education in a formal school to children within age ranges of 3-6 years as a foundation for other levels of education. Early childhood education is identified with many benefits which, according to Taguma, Ineke and Kelly (2012), include achieving adequate child welfare, strong social and economic base for lifelong learning. Based on the numerous benefits of early childhood education, it has received the attention of the world and seen by policy makers as a way of achieving a base for lifelong learning as well as obtaining support for the educational and social needs of the children and families. To ensure the realization of education for all without barriers such as age, gender, ethnicity or culture, the improvement and increase in accessibility of ECE was made the first goal in the Education for All in Dakar Framework (UNESCO, 2000). Children's right to education has also been emphasised by the Universal Declaration of Human Rights and the UN Convention which made ECE part of such rights (Education International, 2010). In the light of this, many countries gave top considerations to the policy and provision of early childhood education. According to Onu and Obiozor (2010), ECE has been adopted to provide 
chances for the children to gain lifelong experiences through the exploration of the environment.

Public schools' participation referred to the level of government involvement in the provision of early childhood education to the public. The provision of quality early childhood education (ECE) is seen as the responsibility of the government. As such, many countries in recent year has included its provision into their electoral agendas. Public identification of gaps in provision and issues with quality in ECE services by ECE schools has formed the main reason for the attention of the government in many countries. In Nigeria, the introduction of National Policy on Education by the government in 1977, mark the first time ECE will get official recognition. The Federal Government Nigeria in the National Policy on Education (2013, section 2, p56) stated that the government shall do the following as regards the provision of ECE otherwise referred to as ECCDE in Nigeria:

Setting and monitoring minimum standard for early childhood education schools.

Developing and disseminating curriculum materials such as the policy, National minimum standard for establishment of Early Childhood Education schools, Implementation Guidelines.

Making provision in teacher education programmes for specialization in early childhood education, and for retraining of teachers.

Ensuring that ECE schools adopt the standard of teachers/pupils ratio in schools

Developing suitable early childhood education curriculum for nationwide implementation.

Supervising and controlling quality of early childhood education schools.

Making provision for production and effective utilization of learning and instructional materials in adequate numbers.

Ensuring that the mother- tongue or language of the immediate community is used as the medium of instruction in ECE schools.

The above points indicate the responsibilities and commitment of the federal government towards the provision of quantitative and qualitative early childhood education in Nigeria. Agusiobo (2003) opined that the Universal Basic Education Programme is all-inclusive and brings within its ambit activities and initiatives for early childhood education. Also, Charles, Madu and Adigun (2016) pointed out that public nursery schools were established in existing public primary schools to share the available facilities as well as teachers, among other things for its provision. This came as a result of the policy mandating the creation of ECE sections in public UBE primary schools. The introduction of basic education brought about increment in the number of public ECE schools in Nigeria. Torpev (2013) believed that education should be made available for those that yearn for it by the government. Though the government bears direct cost such as payment of teachers' salaries, provision of infrastructure, supervision and facilities, among others. The indirect cost, according to Torpev (2013), should equally be provided by the government because some families may not be able to provide them.

In Nigeria, government involvement in the provision of early childhood education, brought about increase in its accessibility in both urban and rural areas. The government ownership of ECE schools in public primary schools has made it easily available for as much as possible number of children to acquire it. However, Etejere, 
Oniyangi, Sheu, Ogunniyi \& Amana (2015) found that the participation of public schools in pre-primary education has not recorded $100 \%$. This lack of completion of participation is believed to be the cause of low standard of education in Nigeria.

UNESCO reported that in Nigeria only $34 \%$ of ECE public schools were in existence. While the communities had the ownership of $21 \%$, the private individual had the ownership of the remaining 45\%. In acknowledgement of the vital role early childhood education play in the lives of the individuals by the government, the year 2004 and 2007 witnessed constant increase in the number of ECE schools in Nigeria (UNESCO, 2010). The Federal government has created ECE units in 111 primary schools in the 36 states of the Federation and the Federal Capital Territory (FCT) Abuja.

The policy for the provision of early childhood education is put in place by the government to guide the schools. However public ECE schools are inadequate with dilapidated and inadequate facilities, insufficient professional teachers as challenges affecting the quality of provision. According to Boocock, (1995) it has been revealed in a reliable cost estimates that most countries need to double annual investment per child to ensure acceptable child-staff ratios and highly qualified staff. Osho, Aliyu, Okolie and Onifade (2014) asserted that there is need for collaborative effort of all stakeholders for successful implementation of Early Childhood Education. Government as expected must provide necessary teaching and learning resources and parents/guardians in their part must enrol their children/wards to make the effort of the government in the provision of early childhood education a successful one.

According to Awoyemi (2013), private schools have become part of educational landscape all over the world, at all levels. Myers (2000) concluded that private sector involvement in education is as a result of common complaint that public schools are administered inefficiently, making poor use of the scarce resources they are able to obtain. It is presumed that privately operated ECE schools are. In Nigeria especially in the north-central zone, the level of regulation of services for early childhood education gives reason for concern as many of the schools are private and unregulated, with unqualified staff and facilities being particularly weak. In most ECE schools, the basic structural standards, such as adequate premises and space for children; child-staff ratios; curriculum implementation; adequate professional early childhood education teachers and supervision are found to be lacking (Akinrotimi \& Olowe, 2016).

Early childhood education, as a component of basic education, though identified by the government as the foundation of other levels of education, has been left in the hands of the private sector from the inception. In Nigeria, early childhood education has been dedicated to the private individuals and religious bodies. UNESCO (2006) stated that private schools were the ones that started the provision of pre-primary education in Nigeria. The private schools were revealed to have the highest number of ECE as stated in a report of an inventory of ECE facilities in Nigeria conducted by FGN/NERDC/UNICEF in 2003. The report shows that $42 \%$ of the sample population of ECE schools were owned by the public. Nearly all the pre-primary education in the country until recently, were owned by the private proprietors. Some of these schools go by the names kindergarten, nursery, 'playgroups' that take care of the children while their parents are at work or go for other engagements. But most of them are 
nursery schools for providing early childhood education (Ejieh, 2006). Based on this, it can be stated that ECE schools serve its purpose of taking care of children while their parent go to work thereby giving the parents the opportunity to contribute to the economic development of the country and also provide basic education that help in laying solid educational foundation in children. However, Organization for Economic Co-operation and Development (OECD) (2011) opined that privately provided education is not only a way of mobilising resources from a wider range of funding sources, it is sometimes also considered a way of making education more costeffective. The cost effectiveness of education can be seen in the individual as such can overcome poverty, have literacy and numeracy skills.

\section{Statement of the Problem}

The aim of every government is to provide favourable environment for the attainment of total development of children in schools. This can be achieved through the provision of adequate and relevant facilities qualified teachers and monitoring of school activities through supervision by school heads and the officers in charge of quality issues in the ministries of education. However, UNICEF (2004) reported that there exist low enrolment level in early childhood education schools in Nigeria with the North having the lowest level of enrolment despite the efforts of government, private individuals and non-governmental organizations in the provision of early childhood education. A study by Ijaiya, Murtala and Akinnubi (2011) found that the lack of adequate facilities and professional teachers are among issues that hinder the successful provision of early childhood education in schools.

While some studies focused early childhood education implementation challenges, some were conducted considering only literacy and numeracy skills thereby creating a gap on issues relating to the levels of public and private participation and early childhood education goal achievement. In the course of filling this gap, this study did a comparative analysis on the goal achievement of early childhood education by public and private schools taking into consideration the level of curriculum implementation, teacher quality, adequacy of facilities and supervision. This became necessary in view of the massive expansion of ECE by public and private schools.

\section{Purpose of the Study}

The purposes of this study were to determine:

the level of participation by public schools in early childhood education in North Central Nigeria.

the level of participation by private schools in early childhood education in North Central Nigeria.

whether there is a significant difference in the level of participation by public and private schools in early childhood education in North Central Nigeria.

\section{Research Questions}

The following research questions were raised to guide the study: 
What is the level of participation by public schools in early childhood education in North Central Nigeria?

What is the level of participation by public schools in early childhood education in North Central Nigeria?

Is there any significant difference in the level of participation by public and private schools in early childhood education in North Central Nigeria?

\section{Research Hypothesis}

$\mathrm{H}_{0}$ : There is no significant difference in the level of public and private participation in early childhood education schools in North Central Nigeria.

\section{Methodology}

The descriptive survey design was used to carry out the study. The study compared the levels of public and private schools participation in Early Childhood Education in the North-central Zone of Nigeria. The population for this study comprised all the 6,064 (2,649 public and 3,415 private) Early Childhood Education school head teachers in Plateau, Kwara, Niger, Benue, Kogi and Nasarawa states in the Northcentral Zone. Random sampling technique was used to select three states (Kogi, Kwara and Niger) out of the six states that made up the North-central Zone, Nigeria as target population. The proportional random sampling technique was used to determine a total of 1,531 respondents which constituted $33 \%$ of the target population (684 public that is $43.5 \%$ and 847 private that is $56.5 \%$ ) of early childhood education school head teachers.

A questionnaire entitled "Public and Private Schools' Participation Questionnaire (PPSPQ) was used for data gathering. The questionnaire consisted of parts A and B. Part A sought general information on respondents such as educational qualification and years in service, while part B gathered information on public and private schools participation. To obtain the average values, ranking position and compare the level of participation by public and private schools in ECE, mean and rank ordering were used to answer the research questions. Also, in order to determine whether there exist significant difference statistically in the level of participation by public and private schools in ECE, inferential statistics of independent t-test was used to test the hypothesis at 0.05 level of significance.

\section{Presentation of Results}

Tables 1 to 2 provided answers to research questions 1 and 2, using mean and ranking order while the hypothesis was tested using inferential statistics at 0.05 level of significance.

\section{Research Question One}

What is the level of participation in early childhood education by public schools in North Central Nigeria? 


\begin{tabular}{llll}
\hline & & \multicolumn{2}{r}{ North Central Nigeria } \\
\hline Table 1: & \multicolumn{2}{c}{ Level of Participation by Public Schools in North Central Nigeria } \\
\hline Levels & Mean & Standard Deviation & Rank \\
\hline Provision of facilities & 24.2 & 13.80 & 4 \\
Supervision & 44.5 & 12.01 & 2 \\
Curriculum implementation & 34.3 & 10.34 & 3 \\
Qualified teachers & 45.1 & 10.03 & 1 \\
\hline
\end{tabular}

Table 1 shows the mean of public schools' participation in terms of the highest and the least level of participation. The table revealed that teacher quality has medium mean of 45.1. This has shown that there are qualified teachers in public ECE schools. Qualified teachers is followed by supervision with a mean of 44.5. This shows that head teachers do carry out frequent observation of learning activities, update instructional materials, encourages and provide opportunities for teachers' professional development in sampled ECE public schools. Furthermore, curriculum implementation with a mean of 34.3 ranked third and average in the level of public schools participation in early childhood education. Provision of facilities has low mean with 24.2. This indicates that provision of facilities is the least level of participation by the public schools in early childhood education.

\section{Research Question Two}

What is the level of participation in early childhood education by private schools in Nigeria?

Table 2: Level of participation of private schools in ECE in North Central Nigeria

\begin{tabular}{llll}
\hline Levels & Mean & Standard Deviation & Rank \\
\hline Provision of facilities & 54.4 & 10.037 & 3 \\
Supervision & 65.6 & 13.801 & 1 \\
Curriculum implementation & 56.7 & 11.176 & 2 \\
Qualified teachers & 42.2 & 9.922 & 4 \\
\hline
\end{tabular}

Table 2 indicates the level of private schools' participation in the provision of early childhood education. Supervision ranked first with a mean of 65.6. This means that private schools provide adequate supervision through observation of teaching and learning activities, checking of lesson notes, provision of conducive environment for teaching and learning, frequent updating of instructional and play materials among others. Furthermore, curriculum implementation with a mean of 56.7 ranked second. This shows that the schools do teach the pupils numeracy and language skills, alphabets, songs and rhymes and simple health habits in private schools. Provision of facilities ranked third with a mean 54.4. This implies that, to some extent, facilities such as classrooms, offices, toilets, playground facilities, toys among others, were made available for easy access and use by the children. Further still, qualified teachers with a mean of 42.2 is the least level of private schools' participation in the provision of early childhood education. 


\section{Hypothesis}

There is no significant difference in the level of participation of public and private schools in early childhood education in Nigeria.

Table 3: Level of Participation of Public and Private Schools in North Central Nigeria

\begin{tabular}{|c|c|c|c|c|c|c|}
\hline Variable & $\mathrm{N}$ & Mean & SD & $\begin{array}{l}\text { Cal. } \\
\text { value }\end{array}$ & t- $p$-value & Remark \\
\hline Public & 676 & 24.25 & 13.80 & \multirow[b]{2}{*}{-3.66} & \multirow[b]{2}{*}{0.000} & \multirow[b]{2}{*}{ Rejected } \\
\hline Private & 835 & 54.25 & 9.92 & & & \\
\hline
\end{tabular}

*Significant level 0.05

The result in Table 3 shows that the p-value (.000) is less than the level of significance of 0.05 . Hence, the null hypothesis which stated that there is no significant difference in the level of provision of facilities in public and private early childhood education schools in Nigeria is rejected. It therefore means there are more facilities such as classrooms, offices, toilets, instructional materials, outdoor facilities among others in private ECE schools (Mean $=54.25)$ than that of the public schools (mean $=24.25$ ). The private sector has higher number of ECE schools despite the fact that all the UBE public primary schools are mandated to establish ECE centres. Nevertheless, most public schools are yet to do so citing lack of adequate facilities as the main reason for not providing ECE in their schools.

\section{Summary of Findings}

In this study, it was found that:

the level of participation of public schools in early childhood education was medium. the level of participation of public schools in early childhood education was high. a significant difference exist in the level of participation of public and private schools in early childhood education.

\section{Discussion of Findings}

The finding in Table 1 indicates that provision of facilities is the least level of participation by the public schools in early childhood education. Even though by constitution Government has the responsibility of making educational policy which serves as guide to the educational system. Funding of early childhood education, even though it is left mainly in the hands of the private sector, is the sole responsibility of the government as stated in the National Policy on Education (2004) and as supported by the UBE (2004) act which pronounced early childhood education to be provided free to children of 3-5 years plus to give the child a foundation in education. Scholars agree that the public investment per child in early education ranges from significantly less to roughly equal to the investment per child in primary school, as young children need more staff than older children to attend to their numerous needs.

The result in Table 2 has shown that private schools has high level of participation in supervision, followed by supervision and curriculum implementation. However, there 
exist low level of participation in the provision of quality teachers by private schools in North Central Nigeria. According to Osho, Aliyu, Okolie \& Onifade (2014) asserted that there is need for collaborative effort of all stakeholders for successful implementation of Early Childhood Education. Government as expected must provide necessary teaching and learning resources and parents/guardians in their part must enrol their children/wards to make the effort of the government in the provision of early childhood education a successful one.

The result in Table 3 shows that there is a significant difference in the level of participation by public and private schools in the provision of early childhood education in Nigeria. In line with this, Etejere, Oniyangi, Sheu, Ogunniyi \& Amana (2015) found that the participation of public schools in pre-primary education has not recorded reliable achievement. UNESCO (2010) reported that in Nigeria only $34 \%$ of ECE public schools were in existence. While the communities had the ownership of $21 \%$, the private individual had the ownership of the remaining $45 \%$.

\section{Conclusions}

It is presumed that the lack of adequate facilities in schools undermine the achievement of adequate curriculum implementation, supervision and competency of teachers. Although the private schools were found to have more facilities in place than public schools, the study revealed that the available facilities were insufficient due to the large number of children using the facilities. Most of facilities were not available in public schools and the available ones were grossly inadequate as the ECE pupils were found to be sharing facilities with primary school pupils. Most of the public schools were found to lack facilities such as toilets, playgrounds, instructional facilities, toys and resting places (beds and mattresses) for children who fall asleep in the classroom.

\section{Recommendations}

Based on the findings of the study, the following recommendations were made:

The government should participate fully in the education of preschoolers, and upgrade the current low level of ECE facilities in public schools.

Private ECE schools should only be issued license to operate upon the satisfaction of prescribed quality guidelines and minimum NCE qualification of teachers employed.

Seminars and conferences should be organised regularly to update and improve the ECE teachers' competency and professional skills.

Frequent visitation of public and private schools by quality assurance officers of ministries of education must be carried out to improve the quality of ECE provision in schools. 


\section{References}

Agusiobo, C. B. (2003). National Case Study Report on the Delivery of Early Childhood Services. Abuja: UNESCO.

Akinrotimi, A. A. \& Olowe, K. P. (2016). Challenges in the implementation of early childhood education in Nigeria; Way forward. Journal of education and practice, 33-38.

Authur, M. (2013). Early Childhood Education an Essential Component of Economic Development: with reference to the new England States. Amherst: Political Economic Research Institute University of Massachusetts.

Awoyemi, O. A. (2013). Resolving the challenges of private primary schools in Nigeria. In P. K. Ojedele, M. Arikewuyo, \& A. Njoku, (Eds) Challenges of Educational Development in Nigeria (pp. 390-427). Ondo: NIEPA.

Biersteker, L.; Ngaruiya, S.; Sebatane, E. \& Gudyanga, S. (2008). Introducing preprimary classes in Africa: opportunities and challenges. In M. Garcia, A. Pence, \& L. Evans, Africa's future, Africa's challenge; Early childhood care and development in Sub-Saharan Africa (pp. 227-248). Washington DC: The World Bank.

Boocock, S. S. (1995). Early Childhood Programs in Other Nations: Goals and Outcomes. The Future of Children; long-term outcome of early childhood programs, 94-114.

Charles, G. E.; Madu, S. \& Adigun, F. A. (2016). Appraisal of the implementation of early childhood education in Owerri education zone 1 of Imo State, Nigeria. Journal of Research and Method of Education, 80 - 85.

Education International (2010). Early childhood education : Global scenario. Belgium: Education International.

Ejieh, U. M. (2006). Pre-Primary Education in Nigeria: Policy implementation and problems. Elementary education online, 58-64.

Etejere, P. A.; Oniyangi, O. S.; Sheu, A. A.; Ogunniyi, M. L. \& Amana, S. B. (2015). An assessment of the implementation of pre-primary education objectives in Nigeria. Journal of Institute for Educational Planning and Administration, $257-264$.

Federal, R. O. (2013). National Policy on Education, Lagos: NERDC.

Ijaiya, N. (2012). Managing early childhood care and development in Kwara State, Nigeria: Problems and Prospect: Early Childhood Education. Journal of Research in Education, 48-60.

Lynne, S. \& Ruzzi, B. B. (2005). Early Childhood Education: Lessons from the States and Abroad. National Center on Education and the Economy. 
Myers, G. R. (2000). The role of the private sector in early childhood care and development. World bank. Washington DC: A paper presented at conference on the early childhood development "investing in our children's future.

OECD (2006). Starting strong II: Early childhood education and care. OECD.

OECD (2011). Lessons from PISA for United States, strong performers in education. OECD publishing.

Ogunyemi, T. F. (2013). Mushroom Private Nursery/Primary schools: The Bane of Qualitative Early Childhood Education in Nigeria. In P. K. Ojedele, M. Arikewuyo, \& A. Njoku, Challenges of Educational Development in Nigeria (pp. 809-826). Ondo: NIEPA.

Onu, V. C.; Obiozor, E. W.; Agbo, W. \& Ezeanwu, C. (2010). Integration and Innovation in Early Childhood Education in Nigeria: Implication for quality teacher production. African Journal of Teacher Education, 209-221.

Osho, L. O.; Aliyu, N.; Okolie, O. \& Onifade, O. (2014). Implementation of Early Childhood Education: A case study in Chanchaga Local Government Area, Niger State, Nigeria. Universal Journal of Educational Research, 119 -125.

Taguma, M., Ineke, L., \& Kelly, M. (2012). Quality Matters in Early Childhood Education and Care. Slovak Republic: OECD.

Torpev, T. F. (2013). Access to Basic Education: Innovation for the Development of Nigeria. In P. K. Ojedele, M. O. Arikewuyo, \& A. Njoku, Challenges of Educational Development in Nigeria (pp. 218 - 240). Ondo: National Institute for Educational Planning and Administration (NIEPA).

UNESCO (2000). Dakar Framework for Action. Paris: UNESCO.

UNESCO (2006). Nigeria Early Childhood Care and Education Programmes. Geneva: UNESCO. 